\title{
Oncopeltus-like gene expression patterns in Murgantia histrionica, a new hemipteran model system, suggest ancient regulatory network divergence
}

\author{
Jessica Hernandez, Leslie Pick ${ }^{*}$ (1) and Katie Reding
}

\begin{abstract}
Background: Much has been learned about basic biology from studies of insect model systems. The pre-eminent insect model system, Drosophila melanogaster, is a holometabolous insect with a derived mode of segment formation. While additional insect models have been pioneered in recent years, most of these fall within holometabolous lineages. In contrast, hemimetabolous insects have garnered less attention, although they include agricultural pests, vectors of human disease, and present numerous evolutionary novelties in form and function. The milkweed bug, Oncopeltus fasciatus (order: Hemiptera) —close outgroup to holometabolous insects —is an emerging model system. However, comparative studies within this order are limited as many phytophagous hemipterans are difficult to stably maintain in the lab due to their reliance on fresh plants, deposition of eggs within plant material, and long development time from embryo to adult.
\end{abstract}

Results: Here we present the harlequin bug, Murgantia histrionica, as a new hemipteran model species. Murgantiaa member of the stink bug family Pentatomidae which shares a common ancestor with Oncopeltus 200 mya -is easy to rear in the lab, produces a large number of eggs, and is amenable to molecular genetic techniques. We use Murgantia to ask whether Pair-Rule Genes (PRGs) are deployed in ways similar to holometabolous insects or to Oncopeltus. Specifically, PRGs even-skipped, odd-skipped, paired and sloppy-paired are initially expressed in PR-stripes in Drosophila and a number of holometabolous insects but in segmental-stripes in Oncopeltus. We found that these genes are likewise expressed in segmental-stripes in Murgantia, while runt displays partial PR-character in both species. Also like Oncopeltus, E75A is expressed in a clear PR-pattern in blastoderm- and germband-stage Murgantia embryos, although it plays no role in segmentation in Drosophila. Thus, genes diagnostic of the split between holometabolous insects and Oncopeltus are expressed in an Oncopeltus-like fashion during Murgantia development.

Conclusions: The similarity in gene expression between Murgantia and Oncopeltus suggests that Oncopeltus is not a sole outlier species in failing to utilize orthologs of Drosophila PRGs for PR-patterning. Rather, strategies deployed for PR-patterning, including the use of E75A in the PRG-network, are likely conserved within Hemiptera, and possibly more broadly among hemimetabolous insects.

Keywords: Harlequin bug, Hemiptera, Insect model system, Segmentation, Pair-rule genes, E75A, Murgantia histrionica, Pentatomidae

*Correspondence: Ipick@umd.edu

Department of Entomology, University of Maryland, 4291 Fieldhouse

Drive, College Park, MD 20742, USA

(c) The Author(s) 2020. This article is licensed under a Creative Commons Attribution 4.0 International License, which permits use, sharing, adaptation, distribution and reproduction in any medium or format, as long as you give appropriate credit to the original author(s) and the source, provide a link to the Creative Commons licence, and indicate if changes were made. The images or other third party material in this article are included in the article's Creative Commons licence, unless indicated otherwise in a credit line to the material. If material is not included in the article's Creative Commons licence and your intended use is not permitted by statutory regulation or exceeds the permitted use, you will need to obtain permission directly from the copyright holder. To view a copy of this licence, visit http://creativeco mmons.org/licenses/by/4.0/. The Creative Commons Public Domain Dedication waiver (http://creativecommons.org/publicdomain/ zero/1.0/) applies to the data made available in this article, unless otherwise stated in a credit line to the data. 


\section{Introduction}

Much of our understanding of the genetic and molecular mechanisms underlying animal development, morphology and physiology is based on studies of a handful of well-established model systems. Approaches in comparative biology have built upon discoveries from these model systems, revealing highly conserved genes and pathways shared across phyla. For example, based on work in the pre-eminent model organism Drosophila melanogaster, this approach revealed unexpected and conserved roles of Hox genes in embryonic development and Pax genes in eye development throughout Metazoa (reviewed in [1-5]). However, to discover novel genes and mechanisms, new model systems are required $[6,7]$. Insects are ideal model systems not only because of their short life cycles and embryos that can be collected in large numbers and readily manipulated, but also because insects represent the majority of terrestrial species on our planet, occupy diverse habitats on land and water, and display extensive diversity in morphology, behavior and more [8]. Most emerging insect model systems have focused on the group of holometabolous insects, to which Drosophila belongs (for examples, see [9-13]).

Hemiptera, a close outgroup to holometabolous insects, is a large order of insects, with $>85,000$ species identified to date [14]. The piercing-sucking feeding mechanism seen within this clade enables many species to feed on plants, making many of them agricultural pests (e.g., aphids, scale insects, white flies, kudzu bug, stink bugs, psyllids), and even on humans in the case of kissing bugs, allowing them to vector human disease. The milkweed bug, Oncopeltus fasciatus, is easily reared in the lab on a simple diet of sunflower seeds and water, and has recently emerged as an excellent model system for this group of hemimetabolous insects. It was noted as early as the 1970s that "[t]here are very few basic biological or entomological problems for which the milkweed bug would not be a good experimental animal" [15]. In fact, prior to the explosion of Drosophila molecular genetics, Oncopeltus was used as a model for developmental studies [16]. More recently, the development of tools to examine and manipulate gene expression [17-19] and publication of transcriptomes and genome sequences [20-22] has moved Oncopeltus to "prime model status" [23]. Because of the practical importance of Hemiptera, the diversity within this order, its phylogenetic position, and because progress on Oncopeltus has revealed novelties in morphology and molecular mechanisms (see below), we are seeking to establish additional models within this clade and report here the development of the harlequin bug, Murgantia histrionica, as a new hemipteran model species. Unlike Oncopeltus, Murgantia is a major pest of cruciferous vegetables and thus the development of genetic tools for this species may be useful for pest control.

Research on early embryonic body plan establishment in Drosophila has revealed that sets of regulatory genes act in a hierarchy to sequentially subdivide the embryo into increasingly specified body regions, culminating in the establishment of repeated segmental units along the anterior-posterior axis [24]. Mutations in the pair-rule genes (PRGs) result in loss of alternate body segments and most PRGs are expressed in stripes in the primordia of every other segment (PR-stripes) - the alternate segmental units missing in corresponding mutants (e.g., [25-27]. Segment polarity genes, the next set of genes to act in the regulatory hierarchy, impact the development of equivalent portions of each body segment and are expressed in stripes in the primordia of every segment (segmentally). PRGs regulate the expression of segment polarity genes such as engrailed and wingless, with alternate segmental stripes missing in PRG mutants [28, 29]; for example, in Drosophila, Fushi tarazu (Ftz) directly regulates the expression of alternate engrailed stripes [30, 31].

Drosophila is a holometabolous insect with a derived mode of segmentation in which all segments are specified more or less simultaneously during the blastoderm stage. However, in most insect orders, segments are added sequentially to the germband, with only the most anterior segments specified at the blastoderm stage (sequential segmentation, reviewed in $[18,32,33]$ ). Given this major change in the process of segment formation between Drosophila and more basally branching insects, it seemed likely that the genetic mechanisms underlying segment formation would likewise differ. However, the finding that orthologs of many PRGs are expressed and function as typical PRGs-specifying alternate segmental units-in the sequentially specifying beetle Tribolium castaneum, demonstrated that PR-patterning per se is conserved in sequentially segmenting species. Further, many of the genes involved in this process play similar roles despite differences in the morphological steps involved in segment addition [34]. In particular, in beetles, orthologs of two PRGs (paired (prd) and sloppy-paired (slp)) function in the same way as their Drosophila orthologs, with knockdown leading to 'classical' PR-defects in which alternate segments are missing [34-36]. Other PRG orthologs have dual roles in sequential segmentation: three (even-skipped (eve), runt (run), and odd-skipped (odd)), which are expressed and function exclusively in PR-stripes in Drosophila, are expressed in the segment addition zone (SAZ) in sequentially segmenting holometabolous insects in addition to being expressed in PR-stripes in these species [34, 37]. 
Strong knockdown of these genes results in truncated embryos, with extreme cases of 'head-only' embryos resulting after knockdown of eve in beetles, while weaker knockdown, in which the germband was able to elongate, revealed additional 'classical' PR-like roles for these genes [34, 37]. Additionally, expression data from several other holometabolous insects indicate conserved roles for several orthologs of Drosophila PRGs in pair-rule patterning. For example, eve, run, and prd in the honey bee Apis mellifera; eve, odd, and run in the silk worm Bombyx mori and the parasitoid wasp Nasonia vitripennis, were also shown to have PR-expression patterns [10, 38-42]. The expression and/or function of other PRGs (ftz, hairy, odd-paired and $f t z-f 1$ ) varies even within holometabolous insects [34, 37, 43, 44]. In sum, within the Holometabola, orthologs of five PRGs-eve, odd, prd, slp, and run-are expressed and function in PR-stripes in the primordia of alternate segmental units in broadly divergent species within this clade.

In contrast to this, recent studies in the large milkweed bug, Oncopeltus fasciatus (Hemiptera: Lygaeidae), revealed that orthologs of Drosophila PRGs are expressed segmentally, rather than in a PR-like manner, more similar to segment polarity genes in Drosophila $[45,46]$. Yet PR-like patterning does occur in this species; Of-E75A is expressed in PR-stripes and knockdown resulted in PR-like defects [47]. Interestingly, E75A does not have PR-function in Drosophila [48, 49]. Thus, PR-patterning appears to involve a different set of regulatory genes in Oncopeltus than in holometabolous insects. To ask whether these differences in the expression and function of PRG-orthologs in Oncopeltus compared to holometabolous insects is species-specific or a feature of other hemipterans, we used the harlequin bug, Murgantia histrionica, as a model system. With an estimated divergence time of $\sim 200$ million years from Oncopeltus [5052], Murgantia and Oncopeltus are distant relatives both belonging to the order Hemiptera and infraorder Pentatomomorpha (Fig. 1a), a species-rich group with over 40,000 members $[53,54]$. Here we show that Murgantia can be adapted to laboratory conditions and maintained as a breeding colony for many generations. We focused on a set of genes that are diagnostic of differences between holometabolous insects and Oncopeltus (E75A,

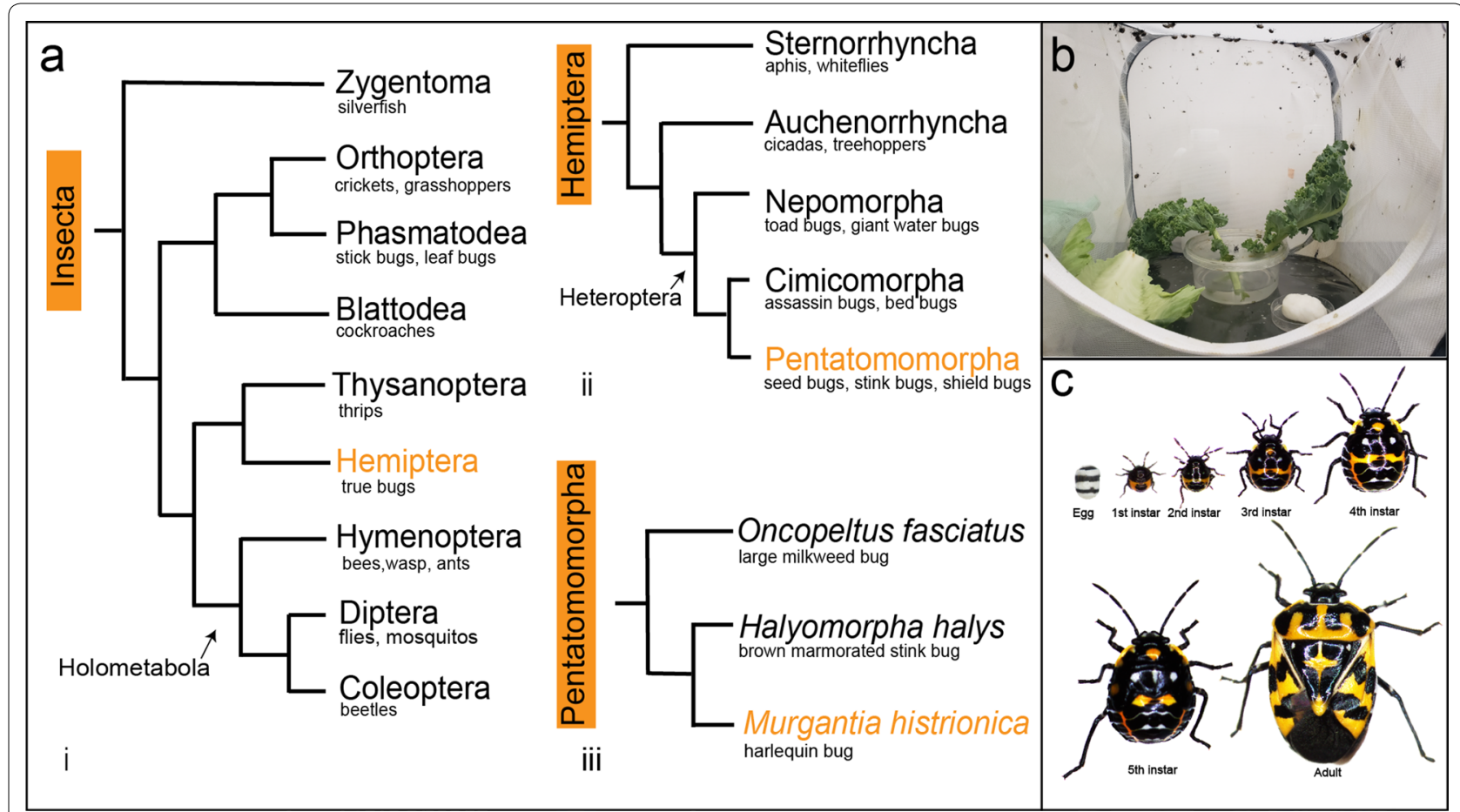

Fig. 1 Phylogenetic context and life cycle of Murgantia histrionica. a Phylogenetic context of Murgantia. Trees are based on Misof et al. [54] and Li et al. [51]. (i) A condensed cladogram that includes some insect orders. Murgantia belongs to the order Hemiptera (colored orange) (ii) Shows a cladogram of Hemiptera, including some major suborders: Sternorrhyncha, Auchenorrhyncha and Heteroptera. Murgantia is a member of Heteroptera and the Pentatomomorpha superfamily (orange text). (iii) Murgantia's relationship to Oncopeltus fasciatus (large milkweed bug) and Halyomorpha halys (brown marmorated stink bug). b Laboratory cage set up for Murgantia. Embryos are allowed to hatch and grow to the second instar in a small petri dish with a piece of wet cotton and kale. They are provided kale three times a week and kept in mesh cages $(12 \times 12 \times 12$ in) at $25^{\circ} \mathrm{C}$. A source of water can be provided (e.g. a wet cotton). c The life cycle of Murgantia. Our lab colony was observed to have five nymphal stages 
eve, odd, runt, prd, and slp) and found that Murgantia orthologs are expressed in an Oncopeltus-like fashion. This suggests that the roles of these genes are shared among Hemiptera and possibly other hemimetabolous insects. In addition to its utility for basic research, Murgantia is a pest of cruciferous vegetables and progress on molecular genetics approaches in this species can lead to novel pest control strategies.

\section{Results}

\section{Establishment of Murgantia as a lab model system}

To serve as a viable model system for molecular genetic studies, organisms must be amenable to long term lab culturing, have a reasonably short life cycle, produce a large number of embryos, and molecular protocols must work well [6]. Before proceeding with genetic analyses, we assessed the feasibility of rearing Murgantia in the lab. We established lab colonies from field-collected Murgantia in summers of 2016 and 2017 and have maintained that colony continuously since that time. As described in the Methods, Murgantia were reared on a diet of fresh organic kale and cabbage leaves with wet cotton as a water source at $25{ }^{\circ} \mathrm{C}, 50 \%$ relative humidity, 16:8 light: dark cycle (Fig. 1b). Males can be readily distinguished from females by the lateral lobes of the genital capsule which are externally visible (arrows, Additional file 1: Fig. S1). Adults typically began mating 10-15 days after their last molt. In each cage, adults began laying eggs soon thereafter, first $1-2$ clutches (12-24 eggs) per cage in $24 \mathrm{~h}$ and up to 7-8 clutches (84-96 eggs) in $24 \mathrm{~h}$ during their egg-laying peak, decreasing after 3 weeks. Embryos usually hatched 5-6 days after egg laying (AEL). A total of five nymphal stages were observed (Fig. 1c). The first instar lasted 4-5 days; the second, third and fourth instars each lasted 6-7 days; and the fifth and final nymphal instar lasted about 11-13 days. Thus, under our rearing conditions, development from egg to adult took 38-45 days. While rearing on fresh food was effective, we have also tested whether Murgantia can be grown on a diet of seeds, similar to Oncopeltus. Preliminary results show that adults can survive on water and seeds (spider flower plus sunflower) though fecundity appears to be lower than those reared on kale/collard greens and cabbage (data not shown).

In order to understand embryogenesis in Murgantia, we performed nuclear staining of embryos carefully staged at $25{ }^{\circ} \mathrm{C}$ (Fig. 2). During the first $12 \mathrm{~h}$ AEL, nuclear division occurs and nuclei were observed at the periphery of the yolk. At the end of the first $24 \mathrm{~h}$, invagination of the germband began at the posterior with cells aggregating at this site (Fig. 2a, arrowhead). For the next $24 \mathrm{~h}$, the germband elongated along the ventral side of the embryo with segments added at the posterior end in the segment addition zone (SAZ) (Fig. 2b, asterisks). In early germbands, clear morphological segmentation was observed only in the thoracic region; as the germband elongated, abdominal segments were added at the posterior, later becoming clearly morphologically segmented. At $48-60 \mathrm{~h} \mathrm{AEL}$, a fully elongated germband with gnathal and thoracic appendages was observed (Fig. 2c).

To establish whole mount in situ hybridization and immunohistochemistry in Murgantia, we used engrailed (en), which is expressed in a highly conserved pattern at the border of each segment in developing arthropods and serves as a segmental marker across species [55-58]. The major challenge to isolating and fixing embryos for visualization of gene expression was that embryos are well-protected by a thick chorion that was difficult to penetrate. We found that immersion of embryos in hot water, followed by boiling and an extended time on ice facilitated physical removal of the pseudoperculum (anterior cap of the chorion, Additional file 2: Fig. S2) which was necessary to allow fixative to access the embryo. In addition, incubation with xylene softened the chorion and facilitated dissection (see Methods for details). In late blastoderm-stage embryos, Mh-en was expressed in six stripes, suggesting that six segments are established in this species before germband elongation (Fig. 2di). Mh-en stripes were added as the germband elongated, presumably marking each segment (Fig. 2dii). Similarly, $M h$-En was detected in segmental stripes by immunohistochemistry using monoclonal anti-Engrailed antibody 4D9, (Fig. 2diii). Overall, these experiments demonstrate that lab rearing and basic molecular genetic approaches to examine gene expression are effective in Murgantia. While no Murgantia histrionica genome has been sequenced yet, the USDA ARS has listed this species as a likely candidate for genome sequencing as part of its Ag100Pest initiative [59].

\section{Murgantia E75A is expressed in PR-stripes}

We chose a set of genes that are diagnostic of the difference between PRG-ortholog expression in Oncopeltus and in holometabolous insects to determine whether the genetic basis of segmentation in Murgantia is similar to one of these. E75A is expressed in PR-stripes in Oncopeltus but not in Drosophila and, to date, is the only PRG identified in Oncopeltus [46, 47]. In Murgantia, Mh-E75A was first detected broadly in the anterior portion of early blastoderm-stage embryos (Fig. 3a). One clear Mh-E75A stripe appeared at the center of the embryo (Fig. 3b, arrowhead), as another stripe began to resolve from the anterior domain of expression (Fig. 3b). Another stripe appeared posterior to this center stripe (Fig. 3c, arrowhead). As germband invagination began, $M h-E 75 A$ was observed in three clear stripes (Fig. 3d). Based on the finding that en 


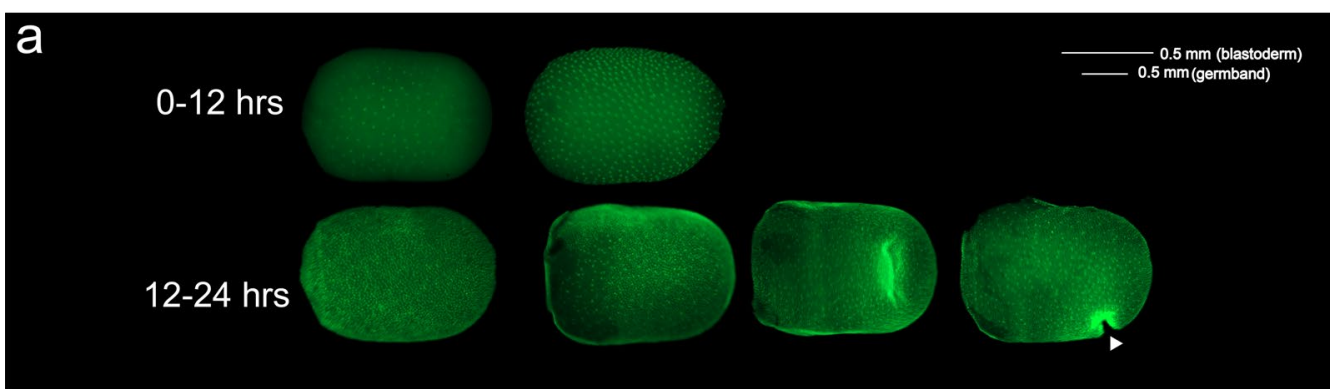

b
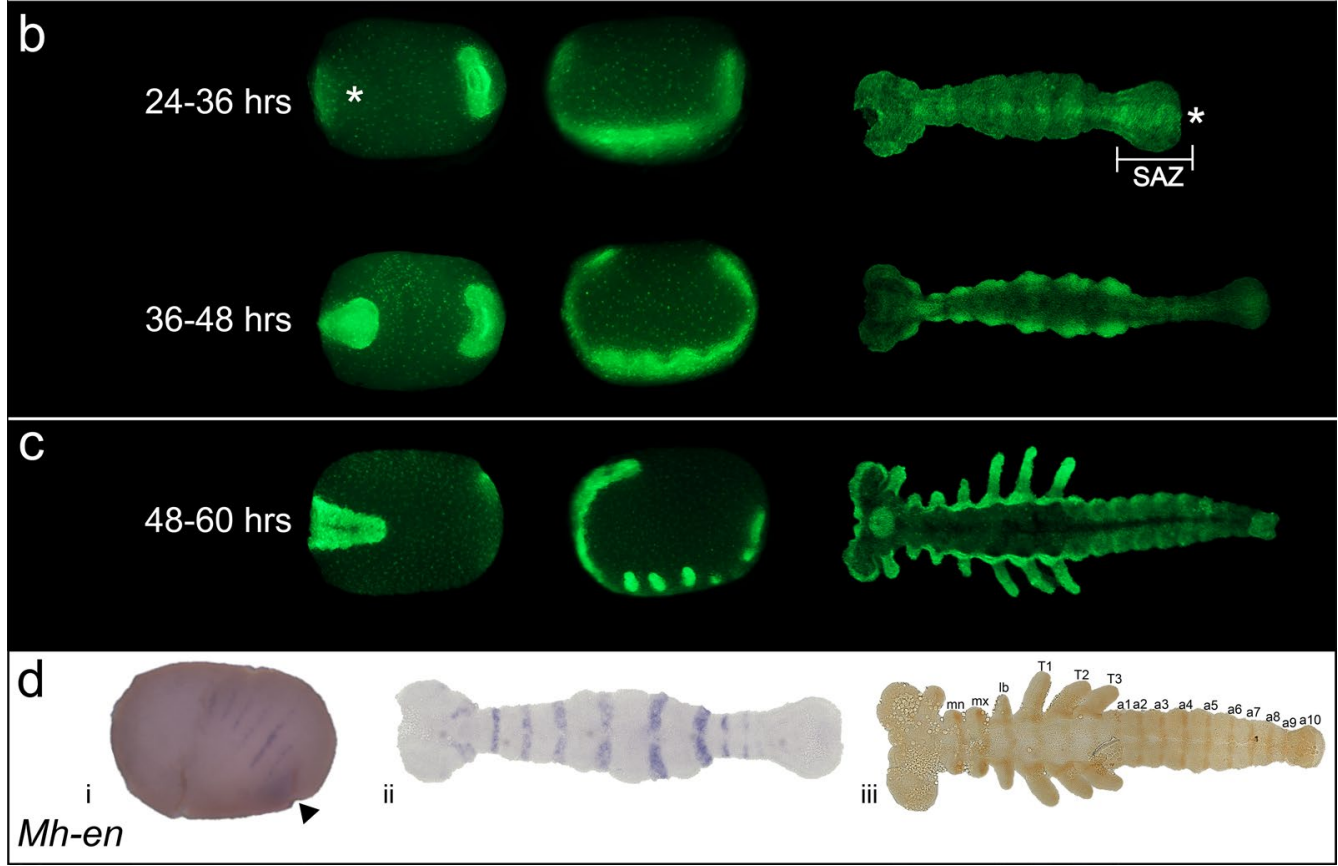

Fig. 2 Embryogenesis and engrailed expression of Murgantia histrionica. Photos of embryos representing the first $60 \mathrm{~h}$ of Murgantia embryogenesis at $25^{\circ} \mathrm{C}$ are shown. Embryos are shown with the anterior to the left. a During the first $12 \mathrm{~h}$ nuclei divide to give rise to an early, likely syncytial blastoderm stage. This continues until invagination occurs at the posterior (indicated by arrow) and the germband begins to grow along the ventral side of the embryo. $\mathbf{b}$ Germband elongation continues for the next $24 \mathrm{~h}$ with segments added at the segment addition zone (SAZ). $\mathbf{c}$ During the next $12 \mathrm{~h}$ a fully elongated germband develops and appendages are visible. Asterisks indicate posterior end of germband. $\mathbf{d}$ Expression of engrailed in Murgantia. (i) Mh-en is expressed in six stripes in the late blastoderm. (ii) Mh-en is expressed in every mature segment during germband elongation. (iii) Expression of Engrailed was examined by immunohistochemistry using the monoclonal antibody 4D9 and a fully elongated germband. (Note that this antibody can detect both En and Invected but we have not as yet isolated Mh-invected and do not know if its expression overlaps with Mh-en.)

was expressed in six stripes at this stage (Fig. 2di), we conclude that these domains of $E 75 \mathrm{~A}$ expression correspond to the primordia of alternate segments and thus the pattern represents classic PR-expression. Mh-E75A continued to be expressed during germband elongation. In early germbands, $M h-E 75 A$ was expressed in two stripes anterior of the SAZ (Fig. 3e, f). In later germbands, one obvious stripe was observed with a second stripe resolving in the center of the SAZ (Fig. 3g, asterisks). Later, $M h-E 75 A$ continued to be expressed in the SAZ with older stripes disappearing anteriorly while two stripes remained in the center of the SAZ (Fig. 3h). The number and spacing of $M h-E 75 A$ stripes in the blastoderm, as it compares to Mh-en expression at the same stage, suggests a role in PR-patterning. The two-stripe cadence of E75A expression during germband elongation suggests that it has the potential to act as a PR regulator in abdominal segment patterning as well. In sum, $M h-E 75 A$ is expressed in a PR-like pattern, similar to that seen in Oncopeltus.

\section{Mh-run is expressed in stripes in the blastoderm and broadly in the SAZ}

In Oncopeltus, run was the only Drosophila PRG ortholog that showed any PR-like expression [46], making this 


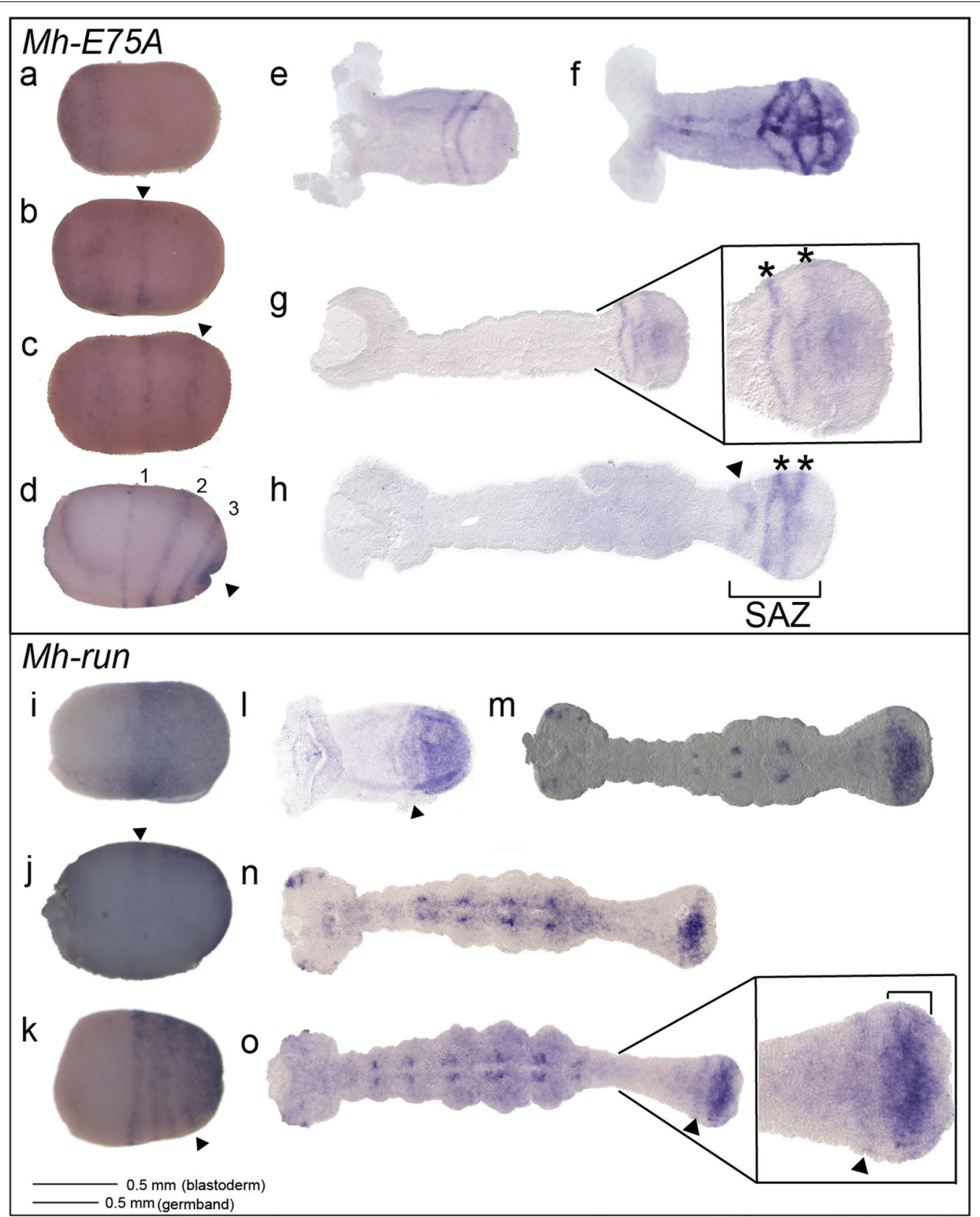

Fig. $3 \mathrm{Mh}$-E75A and Mh-run expression. a Mh-E75A is expressed broadly in the anterior in an early blastoderm-stage embryo (16-24 $\mathrm{h}$ AEL); $\mathbf{b}$ $M h-E 75 A$ continues to be expressed broadly in the anterior with one stripe appearing in the middle of the embryo (arrow head); $\mathbf{c} M h-E 75 A$ resolves into two stripes (arrowhead points to new stripe) with continued expression at the anterior part of the embryo; $\mathbf{d}$ In late blastoderm-stage embryos (24-36 h AEL), invagination of the embryo is beginning to occur (indicated with an arrowhead). At this point Mh-E75A has resolved into three stripes. e-h Mh-E75A expression during germband elongation. Mh-E75A is expressed at the segment addition zone. Asterisks highlight stripes; arrowhead indicates fading stripe. $\mathbf{i}$ Mh-run is expressed in the posterior half of an early blastoderm-stage embryo. $\mathbf{j}$ Mh-run resolves into one stripe with continued expression at the posterior. $\mathbf{k}$ Three stripes of Mh-run are observed in later blastoderm-stage embryos, with one stripe appearing to split. I Mh-run was observed anterior to broad SAZ expression in some early germband-stage embryos (arrowhead); $\mathbf{m}$ In an elongating germband, Mh-run continues to be expressed in the SAZ, and was also observed in dots of expression in the thoracic segments and the head lobes; $\mathbf{n}$ In later germbands, Mh-run was still observed broadly in the SAZ; o Occasionally stripes (arrowhead) of Mh-run were observed anterior to SAZ expression. Embryos are shown with the anterior to the left 
a particularly interesting gene to examine in another hemipteran. Mh-run was first detected broadly in the posterior half of the embryo (Fig. 3i). Expression then resolved into a broad stripe near the center of the embryo with continued expression at the posterior (Fig. 3j, arrowhead). As gastrulation began, three stripes were observed with continued expression in a posterior domain (Fig. 3k, arrowhead). This expression pattern differs from that seen in blastoderm-stage Oncopeltus embryos, where two early broad stripes each appear to split [46]. While we never observed two earlier such stripes of $M h$-run, we cannot rule out that a similar earlier expression pattern exists. It is important to note that Of-run expression was reported to be highly dynamic; given that Murgantia lay fewer embryos than Oncopeltus, this reduced sampling could mask similar variability in expression. Mh-run continued to be expressed during germband elongation, where the expression pattern also differs from that reported in Oncopeltus. Of-run was shown to be expressed in roughly two-segment-wide stripes in the SAZ [46]. In early germbands, Mh-run was observed broadly in the segment addition zone (SAZ); occasionally, a stripe of expression anterior to the SAZ was also observed (Fig. 3l, arrowhead). In older germbands, $M h$ run was expressed in two dots in each segment, possibly in the central nervous system, with continued expression of a thick band in the SAZ, and additional expression in the head lobes (Fig. 3m-o). This expression continued, with an occasional stripe seen anterior to the broad expression in the SAZ (Fig. 3o, arrowhead). In Oncopeltus, Of-run was observed in broad stripes in the anterior SAZ that appeared to split in two as segment primordia left the SAZ, suggesting the potential for PR modulation by Of-run. However, in Murgantia, such two-segmentwide stripes were never observed anterior to the SAZ. These $M h$-run expression patterns in the blastoderm and during germband elongation are reminiscent of $O f$-run expression at these stages, though $O f$-run expression was more characteristic of classic PR patterning.

\section{Mh-odd, Mh-eve and $\mathbf{M h}$-prd are expressed segmentally}

$M h$-odd was detected in a broad domain around the center of the early embryo, absent from the poles (Fig. 4a). This broad expression of $M h$-odd resolved into five stripes in late blastoderm-stage embryos (Fig. 4b), in a manner similar to Of-odd [46]. Mh-odd continued to be expressed during early germband elongation and in fully elongated germbands in four stripes in the anterior SAZ with expression at the head lobes (Fig. 4c, d). This expression showed no PR-like character, similar to what was seen for $O f$-odd.

Mh-eve was first detected in a broad domain in early blastoderm-stage embryos, though absent from the anterior fourth of the embryo (Fig. 4e). In late blastoderm-stage embryos, Mh-eve resolved into five stripes (Fig. 4f), and six stripes were observed as gastrulation began (Fig. 4g), similar to Mh-en (Fig. 2di). In early germbands, Mh-eve was expressed anterior to the SAZ with four visible stripes and a broader region of expression in the central SAZ (Fig. 4h). In older germbands, similar, closely spaced stripes in the anterior SAZ were also observed (Fig. 4i). Double staining with antiEngrailed antibody was performed to compare the segmental expression of $M h$-eve (blue) to En (brown) during germband elongation (Fig. 4j). This revealed that En stripes appear anterior to the SAZ where $M$ h-eve stripes were no longer detectable (arrowheads), showing no temporal overlap of $M h$-eve and $M h$-En. In sum, $M h$ eve was expressed segmentally in blastoderm and later stage embryos, with no hint of PR-register. These $M h$-eve expression patterns are nearly identical to those observed for $O f$-eve at each stage of embryonic development examined $[46,58]$.

Mh-prd expression was first detected in late blastoderm-stage embryos in six stripes (Fig. 4k), presumably in the primordia of every segment. In early germbandstage embryos, Mh-prd was observed in two stripes in the anterior SAZ, as well as faintly in stripes in each more mature segment (Fig. 4l). In later germbands, $M h$ prd was seen in four stripes in the anterior SAZ (Fig. 4m), very similar to the expression patterns of $M h$-eve and $M h$-odd at this stage (Fig. 4i, d). However, unlike Mh-eve and like $M h$-odd, $M h$-prd was also expressed in dots in the head lobes (Fig. 4m, n).

In sum, Mh-odd, -eve and -prd were expressed in very similar patterns to their orthologs in Oncopeltus. For both species, these three genes appear to be expressed in the primordia of every segment of the blastoderm, and then at a register consistent with expression in the primordia of every segment during germband elongation.

\section{Mh-slp is expressed in persistent segmental stripes}

Mh-slp was first observed in the anterior third of early blastoderm-stage embryos (Fig. 5a). This expression resolved into one stripe (Fig. 5b); later, a second stripe was observed (Fig. 5c). Stripes continued to appear posteriorly until six stripes were visible (Fig. 5d). Comparison of the anterior stripe position of $M h$-slp to that of $M h$ odd and Mh-eve (Fig. 4b, f) suggests that the stripes of $M h$-slp seen in early blastoderm-stage embryos (Fig. 5d) are much further anterior than those of eve or odd, and thus likely correspond to pre-mandibular segments. During germband elongation, $M h$-slp continued to be expressed in every segment with no expression detected in the posterior SAZ (Fig. 5e, f). In later germbands, $M h$-slp was observed in every segment with expression 


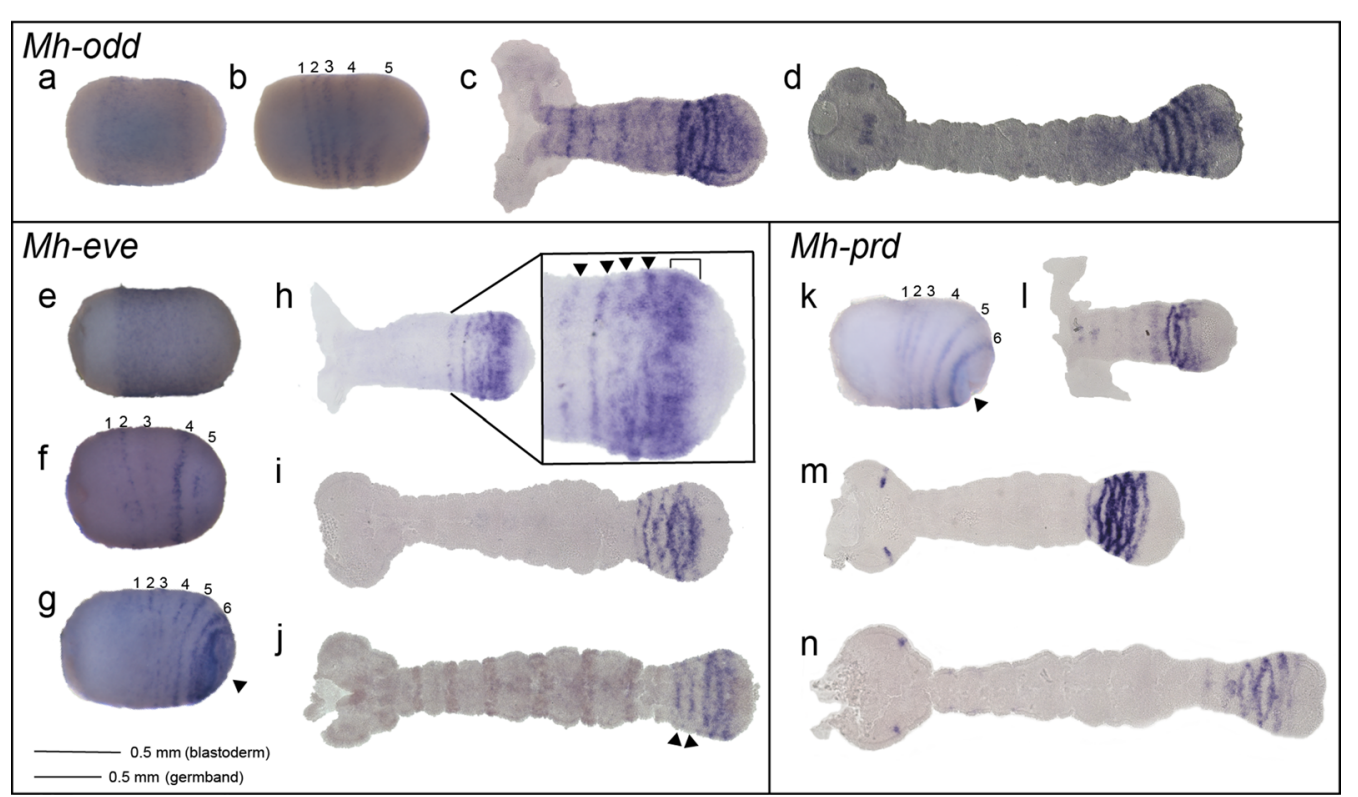

Fig. 4 Mh-odd, Mh-eve and Mh-prd are expressed segmentally. a Mh-odd was first observed in a broad region around the center of the embryo; b Earlier broad Mh-odd expression resolved into five stripes in a later blastoderm-stage embryo, as the germband started to invaginate at the posterior; c Mh-odd was observed in stripes anterior to the SAZ in an early germband; d Anterior SAZ striped expression of Mh-odd continued in later germbands, in addition to dots of expression seen in the head lobes; e Mh-eve was observed in the posterior two-thirds of an early blastoderm-stage embryo (16-24 h AEL). f A later blastoderm-stage embryo (24-36 h AEL) where Mh-eve is expressed in five stripes. $\mathbf{g}$ As invagination (indicated by arrowhead) begins to occur, Mh-eve is expressed in six stripes. $\mathbf{h} \mathrm{In}$ an early germband, there are four stripes (arrowheads) visible with broader expression closer to the posterior SAZ (bracket). $\mathbf{i}$ In a later germband, only four distinct bands are visible and the broader domain of expression to the posterior has disappeared. $\mathbf{j}$ A double stain showing Engrailed in brown and Mh-eve in purple. Arrowheads indicate fading stripes exiting the SAZ $\mathbf{k} M h$-prd is expressed in six stripes at germband invagination. Arrow indicates invagination. I-n Mh-prd expression as germband elongation proceeds. Embryos are shown with the anterior to the left

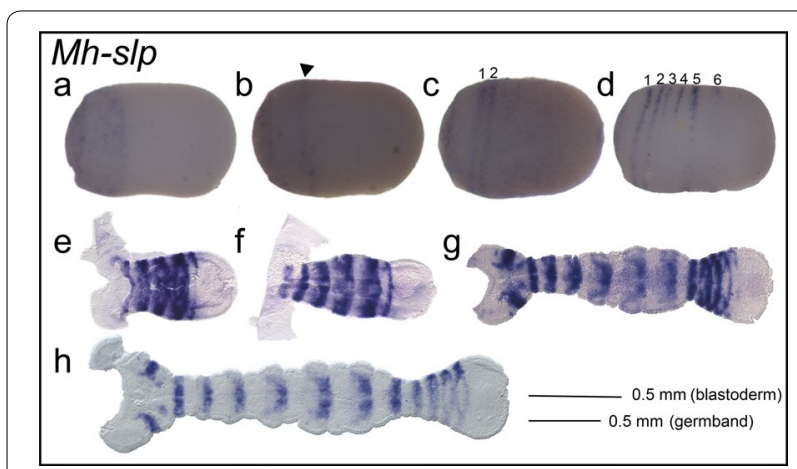

Fig. $5 \mathrm{Mh}$-s/p is expressed in persistent segmental stripes. a $M h$-s/p was observed in the anterior third of an early blastoderm-stage embryo, (16-24 h AEL). b In an embryo slightly older than a, one stripe (arrowhead) of Mh-slp was observed. c Two stripes of $M$ h-s/p were observed in an embryo older than $\mathbf{b}$. $\mathbf{d}$ In a later blastoderm-stage embryo, six stripes of Mh-s/p were observed. $\mathbf{e - h}$ Mh-s/p expression during germband elongation. Mh-s/p is expressed in persistent segmental stripes during germband elongation with expression at the head lobe. Embryos are shown with the anterior to the left, ventral side down concentrated along the midline in older segments. Additionally, expression was observed in the intercalary and antennal segments (Fig. 5g, h). This persistent segmental expression throughout the germband differs from other $M h$-PRG orthologs and is similar to that seen for $O f$-slp.

\section{Conclusions}

We have established the harlequin bug, Murgantia histrionica, as a versatile insect model system. Murgantia are easy to maintain in the laboratory on a diet of fresh organic kale/collard greens and cabbage and can be bred en masse. Murgantia is a hemimetabolous insect with a reasonably short life cycle ( $\sim 6$ weeks from embryo to adult) and produces enough embryos to examine gene expression. As such, this species meets all the basic requirements to serve as a model for molecular genetic analysis. Our lab previously tried to rear another pentatomid, the invasive brown marmorated stink bug Halyomorpha halys, and observed a collapse of our lab colony after three generations, possibly due to infection by a microsporidian [60,61]. We therefore subjected Murgantia to a 'trial period' of lab rearing before beginning experiments to ensure that we could sustain our lab 
colony, and have been able to maintain a healthy lab colony for several years and at least 10 generations.

Methods for examining gene expression in Murgantia were adapted from Oncopeltus protocols and can be performed readily with these modifications on a large number of samples. In addition to their utility as a model system, Murgantia is a pest of cruciferous vegetables (cabbage, kale, etc.). A native of Central America, it was first reported in the United States in 1864 [62]. After its introduction in Texas, the bug spread to other states making its way to most southern states by the late 1890 s. Although it is most active during summer, it has been reported that Murgantia can remain active during mild winters. Over the last decade, warmer winters have led to increased survival and reproduction and larger populations in subsequent seasons [63, 64]. Murgantia damage crops through their piercing-sucking mechanism of feeding, which leaves white blotches on leaves and can destroy crops if populations are large. Elucidation of the genes regulating Murgantia development can lead to non-chemical pest control methods, such as RNA interference.

Here, we used Murgantia as a model system to investigate conservation and variation in PR-patterning mechanisms in insects. We established methods for in situ hybridization and immunostaining; RNAi will be tested as a tool to assess gene function in the future, based on successful use of this technique in Oncopeltus. Previously, we and others had shown that orthologs of Drosophila PRGs are expressed segmentally, rather than in PR-stripes in the milkweed bug Oncopeltus $[45,46,58]$. Specifically, Of-eve, $p r d$, odd, and $s l p$ were each found to be expressed in segmental stripes in the blastoderm with no PR-like expression observed at any stage, while Of-run showed some hint of PR-like expression [45, 46, 58]. In contrast, the Drosophila-like expression of PRGs in PRstripes, in the primordia of alternate segmental units, is shared among a number of holometabolous insects, particularly for the genes eve, prd, slp, run and odd (see Introduction). These findings led us to identify another hemipteran insect for comparative studies. We found that in Murgantia, Drosophila PRG-orthologs are expressed in segmental-stripes in blastoderm-stage embryos with varying expression patterns. Mh-odd, Mh-eve, Mh-prd and $M h$-slp were found to be expressed in five or six stripes in the late blastoderm. During germband elongation, eve, odd, and prd were expressed in a series of stripes in the anterior SAZ showing no PR-register, with additional expression in the head lobes seen for odd and prd. Mh-slp was not observed in the posterior SAZ but was found in persistent segmental-stripes during elongation, marking every mature segment. These expression patterns bear remarkable resemblance to the expression patterns of the corresponding orthologs in Oncopeltus. This suggests that little change in the segmentation network-with regard to any role the Drosophila PRGorthologs might play in this network-occurred over the nearly 200 million years of each lineage's independent evolution.

The similarities in expression patterns between these two species extend to the timing of segmental stripe refinement. Stahi and Chipman [65] showed that expression of four genes-including eve and inv-in segmental stripes in the Oncopeltus blastoderm arise nearly simultaneously, similar to blastoderm segmentation in Drosophila. While we cannot be confident about the precise timing of segmental stripe refinement in Murgantia, we did not observe many intermediate striped expression patterns, suggesting that segmental stripes of Mh-en, -odd, -eve, and -prd arise nearly simultaneously in the blastoderm in this species as well. This pattern is in contrast to the more extreme short-germ mode of segmentation in which segmental stripes arise in an anterior to posterior order. Future studies of blastoderm segmentation in Murgantia could therefore provide further insight into the evolution of different modes of segmentation.

In Oncopeltus, Erezyilmaz et al. [47] showed and we confirmed [46] that E75A, which is not a PRG in Drosophila, is expressed in typical PR-stripes. This nuclear receptor E75A does not have PR-expression in Drosophila and is not known to function in segmentation in any holometabolous insects. Here, we show that $M h-E 75 A$ is expressed in a PR-like pattern during development, the first indication that this gene might be involved in regulating segmentation outside of Oncopeltus. Specifically, $M h-E 75 A$ is expressed in three stripes in the blastoderm, presumably in the primordia of every other segment. During germband elongation $M h-E 75 A$ is expressed in two stripes anterior to the SAZ that disappear in older segments, an expression pattern reminiscent of $O f-E 75 A$. Thus, it seems that there is a different set of genes acting as PRGs within Hemiptera. Whether or not this difference indicates a distinct rift in patterning mechanisms between holometabolous groups and more basally branching insects, or is simply a feature of hemipterans, remains to be investigated.

Here we have found a high level of conservation in expression patterns of PRG-orthologs and E75A in two distantly related hemipterans. While it is not surprising to find greater conservation of expression patterns between these two species than between either and Drosophila, the degree of conservation observed helps provide needed evolutionary context which is missing when network components are examined in highly diverged species in isolation. Thus far, it appears that genes responsible for PR-patterning are wholly different 
in Oncopeltus and Murgantia as compared to holometabolous insects. It will be of particular interest to examine other species in the hemipteran clade to determine if a broader hemipteran segmentation network exists. Future studies of the segmentation networks operating in even more basally branching species will help determine whether an Oncopeltus and Murgantia-like network is ancestral within insects or is Hemiptera-specific. These studies will provide insight into the timing of evolutionary transitions in core body patterning regulators and the mechanisms by which such changes have occurred.

\section{Methods}

\section{Laboratory cultures, life cycle and embryo collection}

Murgantia were collected from kale, cabbage, and spider flower (Cleome spp.) at local gardens. In one year, a garden plot was planted only with Cleome spinosa (Southern Exposure Seed Exchange) which was very effective at attracting Murgantia, suggesting its utility as a trap crop for this species. In the lab, Murgantia were reared in mesh cages $(12 \times 12 \times 12$ in $)$ at $25^{\circ} \mathrm{C}$. A total of eight cages were kept at once, four adults cages ( 70 adults per cage) and four growing nymph cages. Each cage was given one organic kale/collard leaf and one cabbage leaf three times a week. Cages were also supplied with wet cotton as a water source and were lightly misted every other day. Embryos were collected from adult cages to set up new cages. Embryos were kept in small petri dishes, allowed to hatch and grow to the second instar in the dish and later transferred to a clean mesh cage (Fig. 1b). This was done every 2-3 months to keep the colony going. Cages were generally kept for 4 months, after which their fecundity dramatically decreased. Used cages were washed with soapy water followed by bleach and rinsed well with tap water. To collect embryos, fresh food was placed in adult cages and embryos were collected from the leaves. For gene expression analysis embryos were collected during a 8-12 $\mathrm{h}$ window and fixed $12-17 \mathrm{~h}$ after collection. As we observed no egg laying during the nighttime all collections were done during daytime. Since females lay only 12 embryos at a time a collection window of at least $8 \mathrm{~h}$ was necessary to collect enough embryos for experiments. To determine relative ages of embryos, the invagination pore and extent of germband elongation were compared between embryos. Later experiments revealed that Kimwipes could be used to collect embryos by pinning them to the cages with pushpins. In order to count the number of nymphal instars for this species, individual hatchlings were kept in 2 oz. cups with small holes in the lids and cup. A piece of fresh kale was given every day along with a piece of wet cotton. Cups were observed every day and each molt recorded until adulthood. A total of five nymphal stages were observed (Fig. 1c).
CDNA, gene isolation and probe synthesis RNA extraction and CDNA preparation

Embryos were collected every $24 \mathrm{~h}$ for RNA extraction. Approximately 40-50 Murgantia embryos were collected within $24 \mathrm{~h}$, homogenized in $150 \mathrm{ul}$ TRIzol solution (Invitrogen), and stored at $-80{ }^{\circ} \mathrm{C}$ in preparation for RNA extraction. RNA extraction was done as described by the manufacturer. A total of 1 ug RNA template was used for cDNA synthesis. cDNA was prepared following NEB's standard protocol. Briefly, 1ug RNA template was combined with dNTPs (New England Biolabs), Random Primer Mix (New England Biolabs), and water. Tubes were incubated at $65{ }^{\circ} \mathrm{C}$ for $5 \mathrm{~min}$ to denature the RNA and immediately transferred to ice. Transcriptase buffer and RNAse inhibitor (New England Biolabs) were added and incubated at $37^{\circ} \mathrm{C}$ for $2 \mathrm{~min}$. Finally, M-MuLV Reverse Transcriptase (New England Biolabs) was added, and the reaction was incubated at $37{ }^{\circ} \mathrm{C}$ for $50 \mathrm{~min}$ followed by $15 \mathrm{~min}$ at $70{ }^{\circ} \mathrm{C}$ to inactivate the enzyme.

\section{Probe synthesis}

DNA templates for antisense RNA probes were generated by PCR using reverse primers containing the T7 polymerase promoter sequence. Digoxigenin-labeled RNA probes were synthesized from 200 ng of purified PCR product with digoxigenin labelling mix (Roche), RNase inhibitor, and T7 polymerase. RNA transcription reactions were incubated at $37{ }^{\circ} \mathrm{C}$ for $2 \mathrm{~h}$, then RNA was precipitated with $100 \%$ cold ethanol and $6 \mathrm{M}$ $\mathrm{LiCl}$ and incubated overnight at $-20{ }^{\circ} \mathrm{C}$. The pellet was washed with $70 \%$ ethanol, dried, and dissolved in $20 \mu \mathrm{l}$ of nuclease-free water. In order to ensure that the pellet was completely dissolved, tubes were incubated at $37{ }^{\circ} \mathrm{C}$ for 5-10 min.

\section{Gene isolation}

Mh-PRG orthologs were isolated using degenerate primers or primers matching orthologs from Halyomorpha halys (Hhal), based on sequences annotated in the i5k's publicly available draft genome [66]. Rapid Amplification of cDNA Ends (RACE) was performed when necessary. $M h$-en, eve, E75A, and prd were isolated by degenerate PCR with Taq polymerase (see Additional file 3: Table S1 for primer sequences; degenerate primers used to isolate $M h$-eve from [67]). $3^{\prime}$ and $5^{\prime}$ RACE were used to extend Mh-en, eve, E75, and prd using the FirstChoice RLM-RACE Kit (Invitrogen) or the SMARTer ${ }^{\circledR}$ RACE $5^{\prime} / 3^{\prime}$ Kit (Takara Bio). Mh-slp, run, and odd were isolated with Hhal primers, and the SMARTer ${ }^{\circledR}$ RACE $5^{\prime} / 3^{\prime}$ Kit (Takara Bio) was used to extend the $5^{\prime}$ and $3^{\prime}$ ends of Mh-odd. Orthology was determined by phylogenetic and sequence analysis using amino acid sequences of paralogs and orthologs of the target gene from various insect 
species (Additional file 4: Fig. S3; Additional file 5: Fig. S4). Gene trees were constructed for each ortholog using the following homologs. en: en and invected; E75A: E75A and EcR; eve: eve, labial, and proboscipedia; runt: runt, lozenge, runxA, and runxB; odd: odd, brother of odd with entrails limited (bowl), and sister of odd and bowl (sob); prd: prd, gooseberry (gsb), and gooseberry-neuro (gsb$n)$. Gene structure schematics show the regions of each gene that were isolated in this study (Additional file 6: Fig. S5). Note two isoforms of Mh-prd were found, as in Oncopeltus. These differ in their paired box with an insertion of $75 \mathrm{bp}$ found in one isoform (Additional file 6: Fig. S5e). In some cases, the complete coding sequence was isolated as well as the $5^{\prime}$ or $3^{\prime}$ untranslated region (UTR). The sequences have been deposited to GenBank with the following accession numbers: $M h-E 75 A$ (MT235247), Mh-eve (MT235248), Mh-slp (MT235249), Mh-en (MT235250), Mh-prd-A (MT235251), Mh-prd$B$ (MT235252), Mh-odd (MT235253), and Mh-run (MT235254).

\section{Embryo fixation}

Murgantia embryos were fixed using the protocol for Oncopeltus embryo fixation $[46,58,68]$ with some modifications. Appropriately aged embryos were carefully separated from each other under a dissecting scope using forceps and placed in $2 \mathrm{ml}$ tubes ( 35-40 embryos/tube). To begin fixation, $600 \mathrm{ul}$ of boiling water was added to each tube, and tubes were submerged in boiling water for $3 \mathrm{~min}$. Tubes of embryos were then immediately submerged in ice for 15-20 min. Water was removed and replaced with PBST $(0.01 \mathrm{M}$ phosphate buffered saline with $0.05 \%$ TWEEN-20). Under a dissecting microscope, the pseudoperculum (or anterior "cap") of the chorion was removed using fine-tipped forceps (Additional file 2: Fig. S2). PBST was removed and replaced with $1.2 \mathrm{ml}$ of 1:1 12\% paraformaldehyde (PFA):heptane. Tubes were shaken at $200 \mathrm{rpm}$ for $20 \mathrm{~min}$. PFA (bottom layer of liquid) was removed and replaced with $600 \mathrm{ul}$ of methanol. The heptane:methanol was removed, and embryos were washed three times with $100 \%$ methanol. $1.2 \mathrm{~mL} \mathrm{1:1}$ xylene: methanol was added to each tube and tubes were rocked for $1 \mathrm{~h}$ at $\mathrm{RT}$ to soften the chorion for manual dissection. Xylene:methanol was removed, embryos were washed three times with methanol and stored in methanol at $-20^{\circ} \mathrm{C}$.

As dissecting embryos out of their eggshells is fairly time-consuming, this was usually done several days ahead of starting an in situ hybridization. Embryos were removed from storage at $-20^{\circ} \mathrm{C}$ and gradually washed from $100 \%$ methanol into PBST (3 min per wash in $100 \%$, 75\%, 50\%, 25\% methanol diluted in PBST), followed by one 3 min wash in PBST and three rinses with
PBST. The chorion was manually removed under a dissecting microscope using forceps, and embryos were then washed gradually back into $100 \%$ methanol using the aforementioned series of washes in reverse order. Embryos were washed three times with 100\% methanol, methanol was removed and replaced with $1.2 \mathrm{ml}$ of $1: 1$ methanol:heptane in order to remove the vitelline membrane by inverting and manually shaking the embryos in the tubes for 30-45 s. The methanol:heptane mixture was removed, and embryos were washed two times with $100 \%$ methanol. The embryos were washed into PBST using the same methanol gradient as above. Embryos were washed three times with PBST and fixed for $1 \mathrm{~h}$ in $4 \%$ PFA. After fixation, embryos were washed three times with PBST, washed gradually back into $100 \%$ methanol, and stored at $-20^{\circ} \mathrm{C}$ for later use.

\section{In situ hybridization and SYTOX green nuclear staining}

The in situ hybridization protocol described by BenDavid and Chipman [68] for Oncopeltus embryos was used with some modifications. Fixed embryos were gradually washed from $100 \%$ methanol into PBST (3 min per wash in $100 \%, 75 \%, 50 \%, 25 \%$ methanol diluted in PBST), followed by one 3 min wash in PBST and three rinses with PBST and incubated at $60^{\circ} \mathrm{C}$ with hybridization buffer for 3-4 h. Probes were heated for $3 \mathrm{~min}$ at $90{ }^{\circ} \mathrm{C}$ and placed in ice immediately. Probes were used at concentrations of $0.1-1 \mathrm{ng} / \mu \mathrm{l}$. Embryos were incubated with probes at $60{ }^{\circ} \mathrm{C}$ overnight. Embryos were then incubated with pre-warmed hybridization buffer at $60{ }^{\circ} \mathrm{C}$ for $30 \mathrm{~min}$, two times, followed by incubation with prewarmed $2 \times$ SSC (saline sodium citrate) at $60^{\circ} \mathrm{C}, 2 \times \mathrm{SSC}$ at room temperature (RT) and finally $0.2 \times \mathrm{SSC}$ at RT for $30 \mathrm{~min}$. Embryos were washed 3 times with PBST and incubated with $10 \%$ sheep serum in PBST for $2 \mathrm{~h}$ at RT. Sheep serum was removed and replaced with 1:1600 dilution of anti-digoxigenin-AP Fab fragments (Roche) in $10 \%$ sheep serum and incubated for 3-4 h at RT. Embryos were washed 3 times in PBST and kept in PBST overnight at $4^{\circ} \mathrm{C}$. The following day, embryos were washed with PBST for 20 min five times. In preparation for staining, embryos were washed for $15 \mathrm{~min}$ in alkaline phosphatase (AP) staining buffer $\left(100 \mathrm{mM} \mathrm{NaCl}, 50 \mathrm{mM} \mathrm{MgCl}_{2}\right.$, $100 \mathrm{mM}$ Tris-HCl, pH 9.5 and 0.1\% TWEEN-20) and $15 \mathrm{~min}$ in AP-PVA staining buffer $(100 \mathrm{mM} \mathrm{NaCl}, 50 \mathrm{mM}$ $\mathrm{MgCl}_{2}, 100 \mathrm{mM}$ Tris-HCl, pH 9.5, 0.1\% TWEEN-20 and $2 \%$ polyvinyl alcohol (PVA)). BCIP and NBT (Roche) in AP-PVA was used for color detection. SYTOX green staining was done using 1:1000 SYTOX Green (Invitrogen) in PBST for $1 \mathrm{~h}$ at RT after fixation of embryos with $4 \%$ PFA. Blastoderm state embryos were imaged in PBST. Germbands were hand dissected, removing as much yolk as possible, and mounted in 75\% glycerol in PBST. 


\section{Immunohistochemistry}

Embryos were fixed as described above, except that fixation after chorion removal was done for $30 \mathrm{~min}$ only. After fixation, the protocol described by Lu et al. [60] for Halyomorpha embryos was used except that post-fixation was not done after the staining reaction. If background staining was strong, embryos were washed in 50\% methanol in PBST for 5 min and rinsed 3 times with PBST after the color reaction. The monoclonal anti-Engrailed antibody 4D9 (Developmental Studies Hybridoma Bank) was used at a 1:10 dilution. Double staining was performed by combining in situ hybridization and immunohistochemistry protocols. Protein staining was done first with some changes. First, instead of using PBST, freshly prepared PBTH (filtered 1X PBS, 0.1\% Tween-20, $50 \mu \mathrm{g} / \mathrm{ml}$ heparin, and $250 \mu \mathrm{g} / \mathrm{ml}$ tRNA) was used for all steps. Additionally, RNase inhibitor was added to any incubation longer than $1 \mathrm{~h}$. In situ hybridization followed antibody staining as described above. BCIP/NBT staining was done at $4{ }^{\circ} \mathrm{C}$ to decrease background staining and was monitored very closely under a dissection microscope.

\section{Image processing}

Germbands were imaged with an AxioCam MRc camera (Zeiss) mounted on a Zeiss Axio Imager M1. Picture of germbands were taken with a $20 \mathrm{X}$ objective requiring image merging with Adobe Photoshop. Blastoderms were imaged in PBST using an Axiocam 506 color camera mounted on a Zeiss Discovery.V12 SteREO dissecting microscope. SYTOX-stained embryos were imaged using an Axiocam mono camera mounted on Zeiss Discovery. V12 dissecting microscope in the dark.

\section{Phylogenetic trees and gene structures}

Protein sequences were subjected to phylogenetic analysis as described by Reding et al. [46]. Protein sequences of orthologs from various insects were collected and a multiple sequence alignment was generated using MUSCLE. Alignments were then trimmed using AliView and exported as a FASTA file to TOPALi v2.5 where a phylogenetic tree was constructed using the Bayesian algorithm MrBayes. Trees were edited and formatted using MEGA7.

\section{COI barcoding}

To verify the species of our field-collected colony, part of the mitochondrial cytochrome c oxidase subunit I (COI) gene was sequenced and searched against the BLAST non-redundant nucleotide database. DNA was extracted from two clutches of eggs by pestling in 100 ul of DNA extraction buffer (10 mM Tris-Cl pH 8.2, $1 \mathrm{mM}$ EDTA, $25 \mathrm{mM} \mathrm{NaCl}$, and $200 \mu \mathrm{g} / \mathrm{ml}$ proteinase $\mathrm{K})$, incubating at $37^{\circ} \mathrm{C}$ for $30 \mathrm{~min}$, then $95^{\circ} \mathrm{C}$ for $2 \mathrm{~min}$ to inactive the proteinase $\mathrm{K}$, then briefly spun down to pellet the yolk proteins and chorion. PCR was performed using $1 \mathrm{uL}$ of the supernatant with the primers LCO1490 and HC02198 described in Folmer et al. [69] at an annealing temperature of $52{ }^{\circ} \mathrm{C}$ and an extension time of $15 \mathrm{~s}$. The sequence of the PCR product was queried against NCBI's non-redundant nucleotide database and the Barcode of Life Database (BOLD; [70]). The NCBI database search revealed matches to two $M$. histrionica specimens whose sequences have also been deposited in the BOLD database (specimens 1 and 2 in Additional file 7: Fig. S6 with 16/658 and 4/658 mismatches relative to our sequence, respectively). The sequence with highest percent identity match to our own in the BOLD database had just 2/568 mismatches (specimen 4 in Additional file 7: Fig. S6). The COI sequence has been deposited to GenBank with accession number MT238119.

\section{Supplementary information}

Supplementary information accompanies this paper at https://doi. org/10.1186/s13227-020-00154-x.

Additional file 1: Figure S1. Sexing Murgantia A female (left) and a male (right) are shown. Males can be distinguished from females by the lateral lobes of the genital capsule which are externally visible (indicated by arrows).

Additional file 2: Figure S2. Removal of pseudoperculum. a) An intact egg. Pseudoperculum (or cap) is outlined and indicated by arrow. b) An embryo with removed cap (arrow indicates opening). c) A fully dissected embryo.

Additional file 3: Table S1. Primers used in this study.

Additional file 4: Figure S3. Phylogenetic trees. Accession numbers are listed next to each ortholog used. a) Mh-En was compared to other Engrailed and Invected orthologs. b) Mh-E75A was compared other E75A and EcR orthologs. c) Mh-run was compared to RunX ortholog family members: lozenge, runXA, and runXB. d) Mh-odd was compared to odd, sob and bowl orthologs. e) Mh-eve was compared to eve, lab, and $p b$ orthologs. f) Both isoforms of Mh-prd were compared orthologs of prd, gsb, and gsb-n. g) Mh-slp was compared to other slp orthologs and fork head domain-containing genes croc and FoxG. Numbers at nodes represent posterior probability.

Additional file 5: Figure S4. Sequence alignment of Odd-skipped-related genes within Pentatomomorpha. A protein sequence alignment of oddskipped and its paralogs, brother of odd with entrails limited (bowl), and sister of odd and bowl (sob). Motif A is outlined with a black box; Motif $B$ with orange; Motif C with blue; and Motif D with yellow. Odd, sob and bowl all contain Motif C. Motif A and B are found in bowl only; and Motif $D$ in sob only.

Additional file 6: Figure S5. Gene structure schematics. Structure schematic of the genes isolated are shown. Schematics were drawn to show regions isolated. a) The partial sequence of $\mathrm{Mh}$-en isolated includes the homeodomain and the $3^{\prime}$ UTR. b) The partial sequence of Mh-E75A isolated includes the $5^{\prime}$ UTR, the DNA binding domain and the ligand binding domain. C) The partial sequence of Mh-eve isolated includes the homeodomain and the $3^{\prime}$ UTR. d) The full sequence of Mh-odd was isolated, this includes its signature zinc fingers, the $3^{\prime}$ and $5^{\prime}$ UTR. f) Two isoforms of $M h$-prd were isolated. These were designated the names Mh-prd-A and Mh-prd-B. Mh-prd-B contains an insertion of 25 amino acids in the Paired domain. $\mathrm{f}$ ) The partial sequence of $\mathrm{Mh}$-s/p isolated includes 
the fork-head domain with no $3^{\prime}$ or $5^{\prime}$ UTR isolated. g) The partial Mh-run sequence isolated includes the runt domain with no $3^{\prime}$ or $5^{\prime}$ UTR isolated.

Additional file 7: Figure S6. Sequence alignment of $658 \mathrm{bp}$ of the mitochondrial cytochrome coxidase subunit I (COI) gene. The sequence generated for this study from our lab colony is sequence 3 , indicated by a red box. All other sequences were retrieved from the BOLD database; BOLD sequence IDs are as follows: 1) CNCHA926-11.COI-5P; 2) CNCHA1208-11. COI-5P; 4) BBHMA706-12.COI-5P; 5) BBHMA577-12.COI-5P; 6) BBHMA70212.COI-5P. The locations at which specimens were collected is shown in the top row. Nucleotides which differ from the consensus sequence are highlighted.

\section{Acknowledgements}

We thank the cities of College Park and Berwyn Heights and Galen Dively for allowing us access to their community gardens where Murgantia were collected. We thank Judy Wexler, Patricia Graham and Alys Cheatle Jarvela for comments on the manuscript.

\section{Authors' contributions}

$\mathrm{JH}$ carried out the experiments. KR selected and established the new species used in this paper and trained JH. KR, LP and JH designed experiments and analyzed results. LP obtained funding and supervised JH and KR. All authors read and approved the final manuscript.

\section{Funding}

This work was funded by the NIH (R01GM113230) to L.P.

\section{Availability of data and materials}

All data generated or analyzed during this study are included in this published article and its additional files; sequences will be deposited in GenBank upon acceptance of the manuscript for publication.

\section{Ethics approval and consent to participate}

Not applicable.

\section{Consent}

Not applicable.

\section{Competing interests}

The authors declare that they have no competing interests.

\section{Received: 6 February 2020 Accepted: 6 April 2020}

Published online: 22 April 2020

\section{References}

1. McGinnis W, Krumlauf R. Homeobox genes and axial patterning. Cell. 1992;68:283-302

2. McGinnis W, Kuziora M. The molecular architects of body design. Sci Am. 1994;270:58-66

3. Cvekl A, Callaerts P. PAX6: 25th anniversary and more to learn. Exp Eye Res. 2017;156:10-21.

4. Carroll SB, Grenier JK, Weatherbee SD. From DNA to diversity: molecular genetics and the evolution of animal design. 2nd ed. New York: Blackwell Science Ltd.: 2005.

5. Heffer A, Pick L. Conservation and variation in Hox genes: how insect models pioneered the evo-devo field. Annu Rev Entomol. 2013;58:161-79.

6. Abzhanov A, Extavour CG, Groover A, Hodges SA, Hoekstra HE, Kramer EM, et al. Are we there yet? Tracking the development of new model systems. Trends Genet. 2008;24(7):353-60.

7. Moczek AP, Sears KE, Stollewerk A, Wittkopp PJ, Diggle P, Dworkin I, et al. The significance and scope of evolutionary developmental biology: a vision for the 21st century. Evol Dev. 2015;17(3):198-219.

8. Grimaldi D, Engel MS. Evolution of the insects. New York: Cambridge University Press; 2005
9. Patel NH, Condron BG, Zinn K. Pair-rule expression patterns of evenskipped are found in both short- and long-germ beetles. Nature. 1994:367:429-34

10. Binner P, Sander K. Pair-rule patterning in the honeybee Apis mellifera: expression of even-skipped combines traits known from beetles and fruitfly. Dev Genes Evol. 1997;206(7):447-54.

11. Brown SJ, Shippy TD, Miller S, Bolognesi R, Beeman RW, Lorenzen MD, et al. The red flour beetle, Tribolium castaneum (Coleoptera): a model for studies of development and pest biology. Cold Spring Harbor Protocols. 2009;2009(8):pdbemo126.

12. Keller RG, Desplan C, Rosenberg MI. Identification and characterization of Nasonia Pax genes. Insect Mol Biol. 2010;19(Suppl 1):109-20.

13. Yoon Y, Klomp J, Martin-Martin I, Criscione F, Calvo E, Ribeiro J, et al. Embryo polarity in moth flies and mosquitoes relies on distinct old genes with localized transcript isoforms. Elife. 2019;8:e46711.

14. Encyclopedita of Life. https://eol.org/pages/539. Accessed 17 Mar 2020

15. Fair D. Oncopletus fasciatus: a research animal. Ann Rev Entomol. 1974;19:81-96

16. Lawrence PA, Hayward P. The development of a simple pattern: spaced hairs in Oncopeltus fasciatus. J Cell Sci. 1971:8(2):513-24.

17. Angelini DR, Kaufman TC. Functional analyses in the hemipteran Oncopeltus fasciatus reveal conserved and derived aspects of appendage patterning in insects. Dev Biol. 2004;271(2):306-21.

18. Angelini DR, Kaufman TC. Comparative developmental genetics and the evolution of arthropod body plans. Annu Rev Genet. 2005;39:95-119.

19. Liu PZ, Kaufman TC. Kruppel is a gap gene in the intermediate germband insect Oncopeltus fasciatus and is required for development of both blastoderm and germband-derived segments. Development. 2004;131(18):4567-79.

20. Ewen-Campen B, Jones TE, Extavour CG. Evidence against a germ plasm in the milkweed bug Oncopeltus fasciatus, a hemimetabolous insect. Biol Open. 2013;2(6):556-68

21. Panfilio KA, Vargas Jentzsch IM, Benoit JB, Erezyilmaz D, Suzuki Y, Colella S, et al. Molecular evolutionary trends and feeding ecology diversification in the Hemiptera, anchored by the milkweed bug genome. Genome Biol. 2019;20(1):64.

22. Panfilio KA, Angelini DR. By land, air, and sea: hemipteran diversity through the genomic lens. Curr Opin Insect Sci. 2018;25:106-15.

23. Chipman AD. Oncopeltus fasciatus as an evo-devo research organism. Genesis. 2017:55:5.

24. Nusslein-Volhard C, Wieschaus E. Mutations affecting segment number and polarity in Drosophila. Nature. 1980:287:795-801.

25. Hafen E, Kuroiwa A, Gehring WJ. Spatial distribution of transcripts from the s egmentation gene fushi tarazu during Drosophila embryonic development. Cell. 1984;37:833-41.

26. Gutjahr T, Frei E, Noll M. Complex regulation of early paired expression: initial activation by gap genes and pattern modulation by pair-rule genes. Development. 1993;117:609-23.

27. Heffer A, Lohr U, Pick L. ftz evolution: findings, hypotheses and speculations (response to https://doi.org/10.1002/bies.201100019). BioEssays. 2011;33(12):910-8.

28. DiNardo S, Sher E, Heemskerk-Jongens J, Kassis JA, O'Farrell PH. Twotiered regulation of spatially patterned engrailed gene expression during Drosophila embryogenesis. Nature. 1988;332(6165):604-9.

29. Hughes SC, Krause HM. Establishment and maintenance of parasegmental compartments. Development. 2001;128:1109-18.

30. Florence B, Guichet A, Ephrussi A, Laughon A. Ftz-F1 is a cofactor in Ftz activation of the Drosophila engrailed gene. Development. 1997;124:839-47.

31. Yu Y, Li W, Su K, Han W, Yussa M, Perrimon N, et al. The nuclear hormone receptor FTZ-F1 is a cofactor for the Drosophila homeodomain protein Ftz. Nature. 1997:385:552-5.

32. Davis GK, Patel NH. Short, long, and beyond: molecular and embryological approaches to insect segmentation. Annu Rev Entomol. 2002;47:669-99.

33. Peel AD, Chipman AD, Akam M. Arthropod segmentation: beyond the Drosophila paradigm. Nat Rev Genet. 2005;6(12):905-16.

34. Choe CP, Miller SC, Brown SJ. A pair-rule gene circuit defines segments sequentially in the short-germ insect Tribolium castaneum. Proc Natl Acad Sci USA. 2006;103(17):6560-4. 
35. Maderspacher F, Bucher G, Klingler M. Pair-rule and gap gene mutants in the flour beetle Tribolium castaneum. Dev Genes Evol. 1998;208(10):558-68.

36. Choe CP, Brown SJ. Genetic regulation of engrailed and wingless in Tribolium segmentation and the evolution of pair-rule segmentation. Dev Biol. 2009;325(2):482-91.

37. Xiang J, Reding K, Heffer A, Pick L. Conservation and variation of pair-rule patterning mechanisms revealed in Dermestes maculatus. Development. 2017;144:4625-36.

38. Liu W, Yang F, Jia S, Miao X, Huang Y. Cloning and characterization of Bmrunt from the silkworm Bombyx mori during embryonic development. Arch Insect Biochem Physiol. 2008;69(2):47-59.

39. Nakao H. Characterization of Bombyx embryo segmentation process: expression profiles of engrailed, even-skipped, caudal, and wnt1/wingless homologues. J Exp Zool B Mol Dev Evol. 2010;314(3):224-31.

40. Osborne PW, Dearden PK. Expression of Pax group III genes in the honeybee (Apis mellifera). Dev Genes Evol. 2005;215(10):499-508.

41. Wilson MJ, Dearden PK. Pair-rule gene orthologues have unexpected maternal roles in the honeybee (Apis mellifera). PLoS ONE. 2012;7(9):e46490.

42. Rosenberg MI, Brent AE, Payre F, Desplan C. Dual mode of embryonic development is highlighted by expression and function of Nasonia pairrule genes. Elife. 2014;3:e01440.

43. Choe CP, Stellabotte F, Brown SJ. Regulation and function of odd-paired in Tribolium segmentation. Dev Genes Evol. 2017;227(5):309-17.

44. Heffer A, Grubbs N, Mahaffey J, Pick L. The evolving role of the orphan nuclear receptor ftz-f1, a pair-rule segmentation gene. Evol Dev. 2013;15(6):406-17.

45. Auman T, Chipman AD. Growth zone segmentation in the milkweed bug Oncopeltus fasciatus sheds light on the evolution of insect segmentation. BMC Evol Biol. 2018;18(1):178.

46. Reding K, Chen M, Lu Y, Cheatle Jarvela AM, Pick L. Shifting roles of Drosophila pair-rule gene orthologs: segmental expression and function in the milkweed bug Oncopeltus fasciatus. Development. 2019;146:17.

47. Erezyilmaz DF, Kelstrup HC, Riddiford LM. The nuclear receptor E75A has a novel pair-rule-like function in patterning the milkweed bug, Oncopeltus fasciatus. Dev Biol. 2009;334(1):300-10.

48. Bialecki M, Shilton A, Fichtenberg C, Segraves WA, Thummel CS. Loss of the ecdysteroid-inducible E75A orphan nuclear receptor uncouples molting from metamorphosis in Drosophila. Dev Cell. 2002;3(2):209-20.

49. Karim FD, Thummel CS. Temporal coordination of regulatory gene expression by the steroid hormone ecdysone. EMBO J. 1992;11(11):4083-93.

50. Kumar S, Stecher G, Suleski M, Hedges SB. TimeTree: a resource for timelines, timetrees, and divergence times. Mol Biol Evol. 2017;34(7):1812-9.

51. Li H, Leavengood JM Jr, Chapman EG, Burkhardt D, Song F, Jiang P, et al. Mitochondrial phylogenomics of Hemiptera reveals adaptive innovations driving the diversification of true bugs. Proc Biol Sci. 2017;284:1862.

52. Johnson KP, Dietrich CH, Friedrich F, Beutel RG, Wipfler B, Peters RS, et al. Phylogenomics and the evolution of hemipteroid insects. Proc Natl Acad Sci USA. 2018;115(50):12775-80.

53. Weirauch C, Schuh RT. Systematics and evolution of Heteroptera: 25 years of progress. Annu Rev Entomol. 2011;56:487-510.

54. Misof B, Liu S, Meusemann K, Peters RS, Donath A, Mayer C, et al. Phylogenomics resolves the timing and pattern of insect evolution. Science. 2014;346(6210):763-7.
55. Patel NH, Kornberg TB, Goodman CS. Expression of engrailed during segmentation in grasshopper and crayfish. Development. 1989;107(2):201-12

56. Patel NH, Martin-Blanco E, Coleman KG, Poole SJ, Ellis MC, Kornberg TB, et al. Expression of engrailed proteins in arthropods, annelids, and chordates. Cell. 1989;58(5):955-68.

57. Angelini DR, Kaufman TC. Functional analyses in the milkweed bug Oncopeltus fasciatus (Hemiptera) support a role for Wnt signaling in body segmentation but not appendage development. Dev Biol. 2005;283(2):409-23

58. Liu PZ, Kaufman TC. even-skipped is not a pair-rule gene but has segmental and gap-like functions in Oncopeltus fasciatus, an intermediate germband insect. Development. 2005;132(9):2081-92.

59. i5K. Ag100Pest Initiative 2020 http://i5k.github.io/ag100pest.

60. Lu Y, Chen M, Reding K, Pick L. Establishment of molecular genetic approaches to study gene expression and function in an invasive hemipteran, Halyomorpha halys. Evodevo. 2017:8:15.

61. Preston CE, Agnello AM, Vermeylen F, Hajek AE. Impact of Nosema maddoxi on the survival, development, and female fecundity of Halyomorpha halys. J Invertebr Pathol. 2020;169:107303.

62. McPherson JE, McPherson RM. Stink bugs of economic importance in America north of Mexico. Boca Raton: CRC Press; 2000.

63. Wallungford AK, Kuhar TP, Schultz PB, Freeman JH. Harlequin bug biology and pest management in brassicaceous crops. J Int Pest Management. 2011;2:H1-4.

64. McPherson JE. Invasive stink bugs and related species (Pentatomoidea): biology, higher systematics, semiochemistry, and management. Boca Raton: CRC Press; 2018. p. 819

65. Stahi R, Chipman A. Blastoderm segmentation in Oncopeltus fasciatus and the evolution of insect segmentation mechanisms. Proc Biol Sci. 2016:383:1840

66. i5K Consortium. The i5K Initiative: advancing arthropod genomics for knowledge, human health, agriculture, and the environment. J Hered. 2013;104(5):595-600.

67. Damen WG, Weller M, Tautz D. Expression patterns of hairy, even-skipped, and runt in the spider Cupiennius salei imply that these genes were segmentation genes in a basal arthropod. Proc Natl Acad Sci USA. 2000;97(9):4515-9.

68. Ben-David J, Chipman AD. Mutual regulatory interactions of the trunk gap genes during blastoderm patterning in the hemipteran Oncopeltus fasciatus. Dev Biol. 2010;346(1):140-9.

69. Folmer O, Black M, Hoeh W, Lutz R, Vrijenhoek R. DNA primers for amplification of mitochondrial cytochrome c oxidase subunit I from diverse metazoan invertebrates. Mol Mar Biol Biotechnol. 1994;3(5):294-9.

70. Ratnasingham S, Hebert PD. A DNA-based registry for all animal species: the barcode index number (BIN) system. PLoS ONE. 2013;8(7):e66213.

\section{Publisher's Note}

Springer Nature remains neutral with regard to jurisdictional claims in published maps and institutional affiliations.

Ready to submit your research? Choose BMC and benefit from:

- fast, convenient online submission

- thorough peer review by experienced researchers in your field

- rapid publication on acceptance

- support for research data, including large and complex data types

- gold Open Access which fosters wider collaboration and increased citations

- maximum visibility for your research: over $100 \mathrm{M}$ website views per year

At BMC, research is always in progress.

Learn more biomedcentral.com/submissions 